\title{
Agentes confidenciales en México: España y su primer contacto oficial ante la revolución constitucionalista*
}

\author{
Josefina Mac Gregor \\ FF y L-UNAM
}

$\mathrm{E}$ 120 de julio de 1914 llegó a El Paso, Texas, Manuel Walls y Merino para iniciar sus actividades como agente confidencial de España ante la revolución consititucionalista. Este nombramiento se había hecho indispensable $-y$ fue sugerido con anterioridad por el embajador de España en Estados Unidos- por diversos motivos. El primero de ellos, la expulsión de una gran cantidad de españoles residentes en las ciudades de Chihuahua y Torreón -en las postrimerías de 1913 y al iniciarse el año

* Este trabajo forma parte de una investigación más amplia que será presentada como tesis para optar al doctorado en historia en la UNAM. siguiente-, y los numerosos daños sufridos en sus propiedades e intereses en la zona ocupada por los revolucionarios. El segundo, la negativa reiterada de Venustiano Carranza de atender las reclamaciones de extranjeros a través de representantes ajenos al país de origen de los quejosos. Otro motivo más, la animadversión que el constitucionalismo manifestaba abiertamente hacia el ministro plenipotenciario español en México, Bernardo Cólogan y Cólogan, por la que se consideraba su intervención en la Decena Trágica, y porque estuvo acreditado ante el gobierno de Victoriano Huerta cuando la monarquía española, es decir Alfonso XIII, le otorgó su reconocimiento. Podríamos tal vez agregar uno 
más: el relativo éxito alcanzado en sus gestiones por los agentes norteamericanos acreditados ante diferentes grupos revolucionarios.

Si bien otros países europeos podían permanecer a la expectativa amparándose en el gobierno de Estados Unidos o en su propio poderío, ello se debía, fundamentalmente, a que les era factible otorgar protección a sus colonias en la medida en que éstas no eran muy numerosas y se concentraban en las zonas urbanas; situación que no era la de las colonias españolas. ${ }^{1}$ Esta actitud expectante obedecía también a que los intereses de sus conciudadanos no eran atacados de manera tan directa como lo fueron los españoles, ni tampoco dañados físicamente de la manera violenta y sanguinaria como ocurrió en el caso de los chinos.

A pesar de no ser España una potencia de primer orden en ese momento -el cual no era tampoco el mejor para Europa, una vez que estalló la primera guerra mundial-, no podía permanecer inactiva, también por varias razones, frente a los sucesos mexicanos contra sus súbditos. En primer lugar, el número de ellos en tierras mexicanas y la cuantía de sus intereses. ${ }^{2}$

1 La colonia de extranjeros más numerosa en México era la española, y a diferencia de las otras, no se concentraba en las grandes ciudades, sino que se dispersaba por todo el país; se les podía encontrar, incluso, en pequeñas rancherías, vinculados, en su gran mayoría, con actividades comerciales, ya fueran éstas de pequeña o gran escala.

${ }^{2}$ Las fuentes que hacen referencia al número de españoles en México no coinciden en las cifras; se mencionan cantidades que van de los 30000 a los 50000 individuos. Al respecto,
En segundo, porque, no obstante el descalabro de 1898, España se resistía a perder totalmente la influencia que alguna vez había ejercido entre los países de América Latina, pues aún aspiraba a mantener una especie de liderazgo como "Madre Patria", que creía ser todavía.

Si el gobierno de Huerta no había podido consolidarse ni lograr la pacificación del país, como muchos esperaban que lo hiciera -ya porque se creyera que iba a restaurar el régimen porfiriano o porque presentaba la alternativa de las reformas, teniendo como principio el orden-, no quedaban otros caminos que hacer frente a la revolución triunfante o bien abandonar el país como tantos lo hicieron. Los gobiernos extranjeros, cuyos ciudadanos tenían intereses en México, sólo podian optar por lo primero -ya fuera que hubiesen reconocido o no a Huerta-, si es que querian resolver las dificultades o "dar protección" a sus respectivas colonias. España no fue la excepción. Por el contrario, de los países que habían otorgado su reconocimiento al gobierno surgido del Pacto de la Embajada, España fue la primera nación que respondió a la necesidad de establecer algún vínculo con la revolución triunfante. En las

puede consultarse González Loscertales, "Bases", 1979; Perez Herrero, "Algunas", 1981. WaIls, el personaje central de este trabajo, señalaba en sus informes que la cifra ascendía, en 1914, a más de 40000 españoles. "Walls a Riaño, 2 de septiembre de 1914", Archivo Histórico del Ministerio de Asuntos Exteriores de España (ahmuE): H-2559. Tampoco existe certeza en relación con los intereses económicos. En las mismas fuentes puede encontrarse informacion interesante. 


\section{Ysla dela Mocha .}

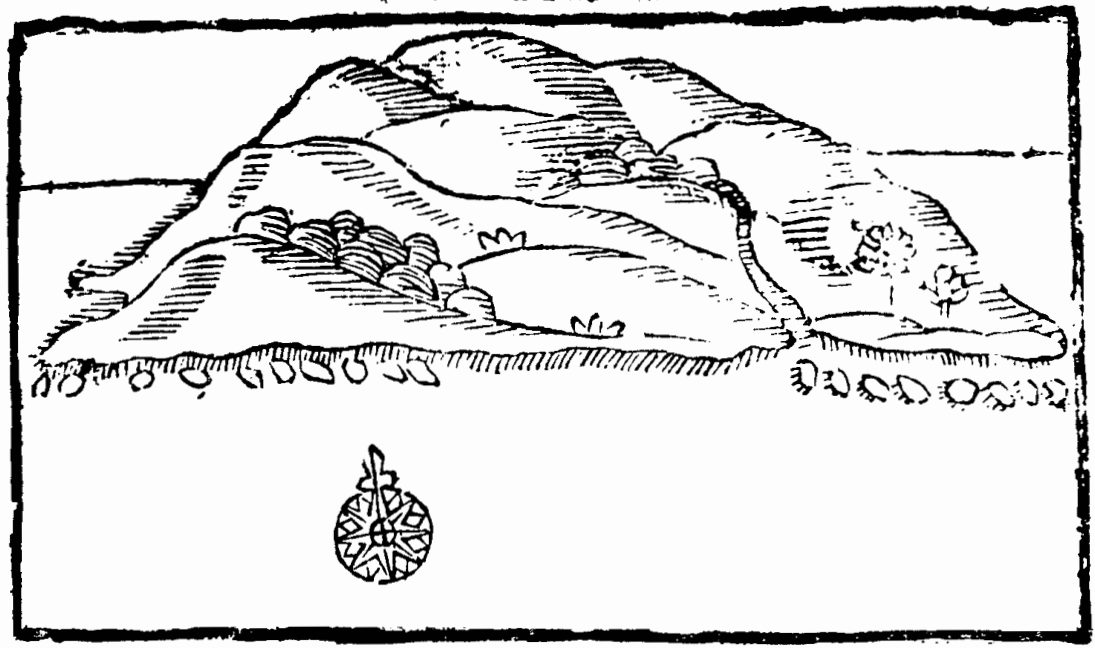

siguientes páginas analizaremos laprimera gestión diplomática española frente a la revolución victoriosa que quitó el poder a Huerta. Veremos también cómo pronto se escindiría y cómo Carranza y Villa serían sus jefes.

\section{ACO'TACIONES AL MARGEN}

Para el caso particular que nos ocupa, sólo dos autores hacen referencia a la gestión de Walls en México: José Fuentes Mares y Carlos Illades. La obra de Fuentes Mares es de carácter general, y se apoya en la documentación que los representantes españoles enviaban a su gobierno. En relación con Walls, quien le parece ignorante del país y prejuiciado, poco es lo que nos dice. Da cuenta de los informes con ob- jeto de detenerse en sus "opiniones nada edificantes sobre el pueblo mexicano", la revolución y sus dirigentes y, así, concluir que "tuerto o derecho, don Manuel Walls y Merino había cumplido su misión" sin que supiéramos cuál era ésta. ${ }^{3}$ Carlos Illades, por su parte, con el apoyo básico de documentos guardados en los archivos mexicanos, los de la legación española en México, los de la legación mexicana en España y la hemerografia enviada por nuestros representantes en España, realiza un estudio sumamente interesante y cuidadoso acerca de los

3 Jose Fuentes Mares, Historia, 1984, pp. 41 50. Precisamente por ese tratamiento tan amplio, el autor no hace un análisis cuidadoso de las diferentes etapas que aborda, ni aprovecha totalmente las fuentes que utiliza. 
españoles en México durante el periodo revolucionario hasta $1915 \mathrm{y}$ las relaciones diplomáticas de México y España para la misma etapa. En relación con Walls indica brevemente, apoyándose en Fuentes Mares, ${ }^{4}$ que se le designó agente confidencial, que se entrevistó con Carranza y con Villa y que el nombramiento de José Caro y Szécheny como ministro plenipotenciario de España dio término a su gestión en México. 5

El examen de los informes de Walls y Merino permiten ampliar la información sobre los conflictos surgidos durante la revolución con los españoles y el propio gobierno espanol; por eso se hace necesario analizarlos pormenorizadamente, en particular porque de estos documentos se desprende que la gestión de Walls no fue tan anodina como hasta ahora se ha percibido y que, en buena medida, trajo aparejado un cambio de actitud de los revolucionarios hacia los intereses hispanos por la oportunidad y tino con que la realizó.

En el Archivo Histórico del Ministerio de Asuntos Exteriores de España

\footnotetext{
${ }^{\prime}$ Illades, Presencia, 1988, pp. v.y. Probablemente el autor no quiso seguir de cerca las abun. dantes citas que de sus fuentes ofrece Fuentes Mares, no obstante que reconoce que el mayor mérito de su obra "es la revisión de las fuentes documentales españolas", porque le parece, al mismo tiempo, que adolece de evidentes deficiencias metodológicas, además de que no evalúa la emigración española a México y sus efectos ni la profundidad de la xenofobia hacia los residentes hispanos, centrándose en las intenciones y motivaciones de los protagonistas, perdiendo de vista el proceso global. Opinión que comparto en todos sus puntos.

5 Illades, Presencia española, 1991, pp. 132133.
}

pudieron localizarse 28 de los 30 informes que Walls envió a Juan Riaño, el embajador español en Washington -siguiendo un camino por demás tortuoso-, 6 y que éste remitió a su vez al Ministerio de Estado. Los despachos se dirigían a Riaño, pues a él se debía su viaje a México. Él había insistido ante su gobierno sobre la necesidad de nombrar un representante de esta naturaleza para atender los asuntos de los españoles en México, ya que a través del gobierno norteamericano poco o nada podía hacerse ante la negativa de Carranza de dar cabida a las reclamaciones hechas mediante intermediarios y su insistencia de que lo haría si se nombraban representantes ante su gobierno. Aun antes de que Huerta renunciara, el embajador creyó pertinente un acercamiento hacia los revolucionarios, pues era en su campo donde se lesionaban los intereses españoles y nada podía hacer el gobierno reconocido por ellos para impedirlo. ${ }^{7}$ La salida de Walls, autorizada el 26 de junio, se realizó el 16 de julio, un día después de la renuncia de Huerta. ${ }^{8}$

6 Por ejemplo, cuando Walls estaba en la ciudad de México, la correspondencia era enviada a Veracruz, por medio de un mensajero de la legación de Estados Unidos. Desde alli un torpedero se encargaba de llevarla a Galveston, donde era depositada en el servicio postal con destino a Washington. Además, los despachos iban dirigidos a James Bryan para que éste los entregara a Riaño con objeto de garantizar que llegaran a su destino.

7 "Riaño al ministro de Estado, 23 de mayo de 1914", AHMAE: H-2259.

8 "Riaño a ministro de Estado, 16 de julio de 1914", AHMAE: H-2559. Asimismo, Riaño fue quien aconsejo a su gobierno que retirara a Bernardo Cólogan y Cólogan de México 
En la correspondencia del embajador español en Estados Unidos al Ministerio de Estado, y en la de éste a su representante, se percibe clara. mente el papel tan importante que Riaño desempeñó para que se definiera la política exterior de España ha. cia México. Su intervención obedecióa diversos motivos. Por un lado, porque, en su búsqueda del apoyo o reconocimiento del poderoso vecino del norte, en Estados Unidos se llevaba a cabo una intensa actividad por parte de las facciones contendientes en México. Por otro, porque, al interrumpirse las relaciones con este país, con motivo del desembarco en Veracruz el 21 de abril de 1914, México dejó sus asuntos en manos de esta embajada. Además, para España, de acuerdo con sus anhelos de un liderazgo en América Latina, era de vital importancia la posición de Estados Unidos frente a México.

Los informes del agente confidencial cubren un periodo de dos meses que va del 22 de julio de 1914 -dos días después de que Walls llegó a $\mathrm{El}$ Paso- al 26 de septiembre del mismo año-fecha en la cual Walls regresó de la misma ciudad fronteriza a la capital norteamericana. Estos documentos hacen un total de 150 cuartillas en las que el agente detalla sus pasos y las tareas emprendidas en torno a su

porque podría recibir alguna afrenta de los constitucionalistas al ocupar estos la ciudad de México, ya que el agente de este bando en Washington le hizo saber que se le pediría que abandonara el país y Ángel de Caso, "caracterizado villista y miembro de la colonia española", le propocionó información en ese mismo sentido. Telegrama del 15 de julio de 1914. misión, a la vez que ofrece sus impresiones personales respecto de la revolución y sus dirigentes, así como de la política exterior de Estados Unidos. ${ }^{9}$

\section{LOS ESPAÑOLES Y LA REVOLUCIÓN CONSTITUCIONALISTA}

El reconocimiento del gobierno espanol al gobierno de Huerta ${ }^{10}$ fue causa indiscutible de asperezas entre los españoles y los revolucionarios constitucionalistas. Para éstos significaba el apoyo moral a su enemigo, y para los españoles, una gran cantidad de problemas insolubles, pues no existía representación oficial que los protegiera y apoyara. Problemas que, además, se fueron agudizando conforme el constitucionalismo se fortalecía en el norte e iba requiriendo de mayores elementos para continuar su avance.

Venustiano Carranza, poco tiempo después de iniciar el movimiento que lo oponía a Huerta y en el que se propuso el restablecimiento del orden constitucional, quiso regularizar la situación respecto de los extranjeros aprovechándola para obtener su reconocimiento. Una primera medida fue reconocer, el 10 de mayo de 1913, el derecho de todos los nacionales y extranjeros a exigir que se les paga-

9 Es decir, en promedio informaba sobre su actividad cada dos días y medio y escribía más de tres cuartillas con sus observaciones. De acuerdo con el propio recuento de Walls, en dos meses y medio recorrió $8692 \mathrm{~km}$ a través del territorio norteamericano y 3413 , en suelo mexicano.

10 El rey Alfonso XIII otorgó el reconocimiento el 28 de abril de 1913. Díaz y Martini, Relaciones, 1977, p. 504. 
ran los daños causados por la revolución. La segunda-ocurrida al mes siguiente-, de carácter interno, consistió en ordenar a todos los jefes militares que actuaran cuidadosamente en relación con las propiedades extranjeras y evitaran, en lo posible, confiscarlas o dañarlas. Durante las conferencias sostenidas en noviembre con el agente norteamericano William $\mathrm{Ba}$ yard Hale, Carranza fijó algunos criterios de su política exterior: que todas las protestas se dirigieran por escrito a su oficina de Relaciones Exteriores para de ese modo poder estudiarlas; se otorgarian amplias garantías para los intereses extranjeros legítimos; se aceptaría que su gobierno había de proteger a los extranjeros, y se rechazaría categóricamente el derecho de cualquier país a inmiscuirse en los asuntos internos de México. ${ }^{11}$

Al inicio de 1914, tres acciones de Villa provocaron incidentes internacionales que obligaron a Carranza a definir aún más su política exterior. La primera fue la orden de confiscar en Durango una mina propiedad de mexicanos, de españoles $y$ de un norteamericano. Las otras fueron dos asesinatos: el de un ciudadano inglés, William Benton, y el de un norteamericano, Gustavo Bauch. Como Estados Unidos presentó las reclamaciones respectivas, Carranza respondió que éstas debían ser expuestas "por los representantes diplomáticos del país que sea ciudadano el extranjero afectado y que tengan autorización de sus gobiernos para hacer

11 Cumberland, Revolucion, 1983, pp. 253. 257; Fabela, Historia, 1985, vol. I, pp. 243-255. tales representaciones o reclamaciones". ${ }^{12}$ Además, dejó muy en claro que de ninguna manera dichas exigencias podían ser tratadas con los jefes militares subordinados a la primera jefatura.

Para los Estados Unidos, esta posición de Carranza parecía exigir una doble representación a los países que habían reconocido a Huerta y, a su vez, sostenía que, de acuerdo con las prácticas internacionales, era factible que una nación que no tuviera representantes acudiera a los de otra para dar protección a sus nacionales. Así, España podía hacerlo en el caso de la mina duranguense, asistiéndose de funcionarios norteamericanos. ${ }^{13}$

La respuesta de Carranza fue terminante: no estaba imponiendo una doble representación, sino una gestión extraofical ante la jefatura del movimiento revolucionario por parte de las naciones interesadas. Asimismo, el Primer Jefe del ejército costitucionalista hizo notar cuáles eran las ofensas que la revolución resentía por parte de España. En primer lugar, la participación de su ministro plenipotenciario en "los asesinatos del presidente y vicepresidente de este país", ${ }^{14}$ $y$, en segundo, el de que "gran parte de los súbditos españoles radicados en la república, han ayudado al gobierno usurpador pecuniariamente $y$ hasta por medio de las armas". Concluía drásticamente al considerar que los países que habían procedido de esta manera "no deberían tener dere-

12 Cumberland, Revolucion, 1983, p. 261.

13 Ibid., pp. 261-262.

14 Sobre la responsabilidad de Cólogan en este suceso, puede encontrarse mayor información en Mac Gregor, México, 1991. 
cho a hacer reclamaciones de acontecimientos desgraciados de que ellos han sido causa por su actitud". No obstante esta observación, Carranza se manifestaba dispuesto a dar garantías a los extranjeros y a mantener la orden de que no fueran molestados de ninguna manera. ${ }^{15}$

15 Fabela, Historia, 1985, vol. I, pp. 263 264. Para Fabela, en esos momentos encargado de la Secretaría de Relaciones Exteriores, la petición de Carranza de un reconocimiento de facto le parecía procedente, después de "poner en claro ante el gobierno de Washington las responsabilidades de aquellos gobiernos incomprensivos e injustos, el británico y el espanol". Para Fabela la prueba de que se tenía la razón en esta exigencia radicaba en el hecho de que "poco después" (cinco meses) España había enviado un agente confidencial ante el Primer Jefe, "no obstante que seguía teniendo en México un enviado extraordinario y ministro
Al proceder de esta manera, Carranza, buscaba un sitio para el México revolucionario enfrentándose al concepto del "interés predominante", de Estados Unidos. Sin embargo, Isidro Fabela, el encargado de la Secretaría de Relaciones Exteriores, interpretaba erróneamente que los países europeos se acogían a la tutela de los Estados Unidos porque aceptaban sin reservas la doctrina Monroe. Cuando menos

plenipotenciario cerca de los gobiernos de la usurpación". Sobre este punto habría que recordar que Walls llegó cuando Huerta ya había renunciado y que España ya había ordenado a Cólogan abandonar México. Debe destacarse también que la única mención que Fabela hace de la misión de Walls es ésta, agregando que le presentó sus cartas credenciales a él mismo "durante la campaña de Chihuahua a la capital mexicana", pp. 266-267.

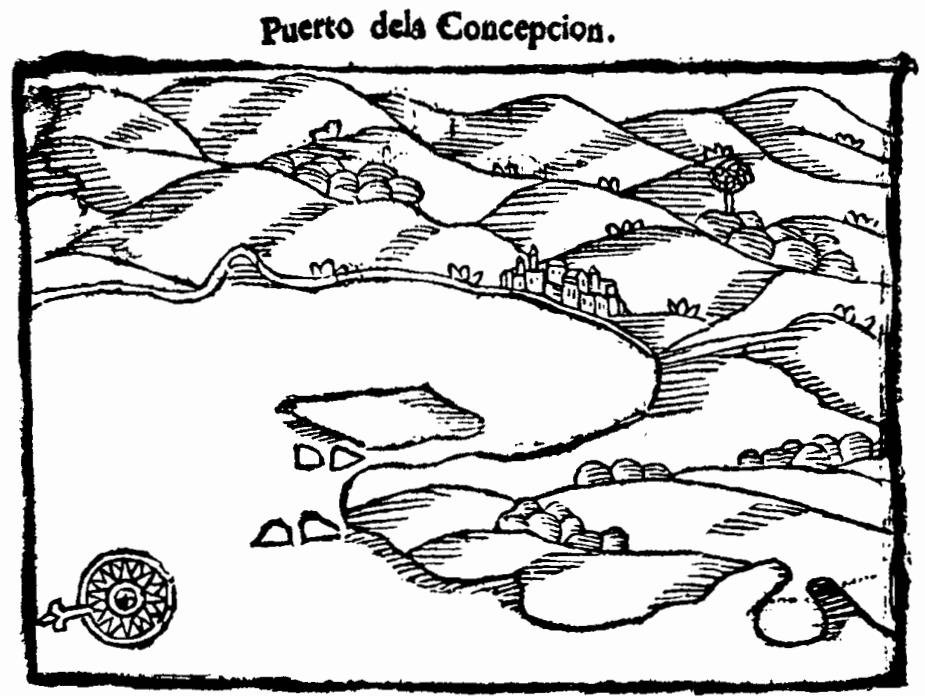


para el caso español, en los documentos de Riaño y de Walls puede apreciarse que España acudía al coloso del norte porque consideraba que la revolución se desarrollaba bajo los auspicios de ese país, y que en consecuencia los lideres revolucionarios atenderían de manera inmediata las observaciones que los funcionarios estadunidenses les hicieran. En su intento por proteger los intereses de los españoles en México, Riaño en particular percibió muy pronto que se debía modificar esta posición inicial -aun cuando se continuara haciendo responsable a Estados Unidos de la alteración de la paz en México- para pasar a tratar directamente con los jefes revoluciona. rios. Este cambio resultaba, incluso, más adecuado a su propósito de fortalecer su influencia en América Latina en un afán de contener la expansión norteamericana, impulsando el hispanismo. ${ }^{16}$

Al finalizar el año de 1913 , al tomar la ciudad de Chihuahua, Villa decidió echar fuera de la población a los españoles residentes en ella. De inmediato, el embajador de España en Estados Unidos solicitó la ayuda del gobierno de ese país para proteger los intereses de los expulsados, y en ese sentido se dieron órdenes a los cónsules norteamericanos. La situación llegó a ser tan desesperada para los 300 expa. triados, que la Cruz Roja norteamericana se tuvo que hacer cargo de ellos en la ciudad de El Paso, en tanto que se procedía a tomar medidas para tras-

16 lbid., vol. I, p. 148. "Correspondencia de Riaño con el ministro de Estado", aHmaE: H-2 559. ladarlos a otro lugar. A fin de resolver este problema, el representante español en Cuba se vio también precisado a intervenir. A costa de la legación se condujo hacia La Habana a los españoles refugiados en Nueva Orleáns, Galveston y otros poblados a los que quisieron ser trasladados. El secretario de la embajada en Estados Unidos recibió órdenes de parte del ministro de Estado para viajar a El Paso $e$ interesarse por los españoles. Autorizados los gastos extraordinarios, las indicaciones en este caso eran:

Conforme deseos españoles hágase información demostrativa de su no inrervención política y proceda $\mathrm{V}$. S. en consecuencia. Ignoro qué medida cabe adoptar para demostrar más todavia España no abandona sus hijos México.

Además, como muchos de los expulsados carecían de recursos, se creó la Junta Especial de Auxilio en el $\mathrm{Ca}$ sino Español de la ciudad de México con objeto de reunir fondos y solventar así las necesidades de los desamparados en El Paso, Texas, y de los "que se encuentren o puedan encontrarse en semejante situación por acontecimientos parecidos". Esta determinación hace presumible que Villa no sólo había actuado en contra de los españoles acaudalados, sino también en contra de muchos que no lo eran.

Las cosas, sin embargo, no parecían cambiar demasiado, pues en febrero el Departamento de Estado de Estados Unidos informó a Riaño que Villa deseaba se le notificara que debía avisar a los españoles en Torreón que abandonaran la ciudad, ya que si ésta caía 
en su poder estaba "dispuesto a pasarlos a todos por las armas". Las gestiones que Riaño inició, parecieron tener éxito poco tiempo después. Al menos, trajeron la esperanza de que no se perseguiría más a los españoles, pues Villa prometió al agente norteamericano respetar la vida de todos los extranjeros "incluso españoles" si no tomaban parte en las hostilidades en la población lagunera. ${ }^{17}$

No obstante las promesas de Villa -quizá porque sólo se referían a Torreón- durante esos mismos meses (febrero y marzo de 1914) los españoles radicados en la zona ocupada por las fuerzas revolucionarias sufrieron la cada vez mayor hostilidad por parte del Centauro del Norte: les fueron confiscados sus bienes y se ordenó su expulsión. Douglas Richmond asegura que en el noroeste las tropas de Rafael Buelna torturaron a comerciantes españoles, y que era frecuente que se les decomisaran mercancias (tabaco, harina, maíz y ganado) para consumo del ejército y de la población o para venderlo en la frontera y así solventar sus gastos de armamento. ${ }^{18}$ Esta persecución cul-

17 "Riańo al ministro de Estado, 13 y 18 de diciembre de 1913 y 6 y 10 febrero de 1914"; "Joseph O'conner [sic.], embajador de Estados Unidos en España al ministro de Estado, 6 y 17 enero de 1914"; "E. Bicknell a J. O'conner, 13 diciembre 1913"; "Ministro de España en Cuba al ministro de Estado 9 enero de 1914"; "Ministro de Estado, marqués de Lema, al ministro de España en Cuba, 9 enero 1914"; "Ministro de Estado a Cárdenas, 20 enero 1914"; "Impreso del Casino Español del 17 de diciembre de 1913", AHMAE: H-2558.

18 Richmond, "Confrontation", 1984, pp. 221-222. Asimismo asegura que en ocasiones los españoles se negaron a vender sus mercancías minó en el momento en que Villa tomaba Torreón el 15 de abril. Alli, "su odio por los españoles se desató", 19 si bien de acuerdo con los ofrecimientos hechos, respetó sus vidas, Villa no sólo se apoderó de sus propiedades, entre las que se contaban 100000 pacas de algodón, sino que los expulsó de la ciudad y del país, por lo que tuvie. ron que refugiarse en El Paso. ${ }^{20} \mathrm{Cum}$ berland afirma que Carranza no estuvo de acuerdo con esta acción de Villa, pero que, ante la imposibilidad de impedirla, optó por hacer caso omiso de ella. Igualmente, este autor considera que éste fue el primer incidente de una larga serie que convenció a $\mathrm{Ca}$ rranza de que Villa era un obstáculo para sus planes.

Todos aquellos que pudieron hacerlo, tomaron de nuevo cartas en el asunto. Así, el ministro plenipotenciario español en Cuba informó que 250 españoles en la ciudad fronteriza solicitaban dinero para trasladarse a Nueva Orleáns, a la vez que indicaba que eran "numerosos" los que se hallaban en La Habana, y que se había formado un comité de auxilio en esta capital para ayudarlos. Debido a la necesidad de rèmediar la situación de los refugiados, solicitaba también que se le autorizaran los gastos que tenía que hacer. Mientras tanto, Riaño seguía in-

para incrementar los precios cuando la escasez se presentó entre 1914 y 1916.

19 Cumberland, Revolucion, 1983, p.116.

20 Riańo informa el arreglo que al respecto hubo y que consistió en el pago de una multa. Sin tener la seguridad en el número, los diplomáticos informaban que los españoles, en las peores condiciones, se encontraban en El Paso en espera de ayuda o de autorización para regresar a sus hogares. 
sistiendo ante el gobierno norteamericano presidido por Woodrow Wilson "quien es en gran parte culpable de lo que ocurre y de los infortunios de los españoles"-, para que les protegiera. Por su parte, en la ciudad de México, la Junta de Auxilios del Casino Español reunió 100000 pesos para sus "compatriotas fugitivos y desvalidos". ${ }^{21}$

La alarma respecto de esta situación llegó a España y fue un instrumento para cuestionar al gobierno en el poder. En la sesión de las Cortes del 12 de mayo, al presentarse el ministro de Estado, el marqués de Lema, a una interpelación, el diputado Soriano aprovechó la oportunidad para preguntar qué se había hecho por los españoles en México. Aseguró tener cartas de españoles que "casi" se avergonzaban de serlo por el desamparo en que los había dejado el gobierno, y concluía: "iQué dirán estos españoles que sos. tienen allí nuestra bandera, cuando aquí se hable de Patria!" El ministro de Estado, por su parte, informó que ya se había comunicado al Senado la ac. tividad desplegada por el gobierno al respecto, y aseguró que se había hecho lo que se podía de acuerdo con sus obligaciones y sus recursos, y que se habían recibido, incluso, testimonios de los españoles refugiados en El Paso agradeciendo los esfuerzos realizados por el gobierno en su favor. ${ }^{22}$ Más que defender los intereses económicos de España en México, que como

21 "Cólogan al ministro de Estado 21 de abril y 27 de mayo de 1914", AHMAE: H-2 559; "Ministro español en Cuba al ministro de Estado, 8 de mayo de $1914^{n}$ y "Riańo al ministro de Estado, 11 de abril de 1914, AHMAE: H-2558.

22 Diario, 1914 , pp. 617-618. tales no existían, pues los españoles acumulaban sus riquezas en México, donde se quedaban a vivir, a los políticos españoles parecía moverlos una suerte de nacionalismo y dignidad por la presencia española en las antiguas colonias. Desde luego, España fue sumamente cautelosa en su política exterior y prácticamente no avanzaba un paso en México sin consultar a sus diplomáticos en Europa, Estados Unidos y países clave de América. Parecía que, si no podía ganar terreno, cuando menos no quería perder el ya obtenido. ${ }^{23}$

Antes de que pudieran prosperar los reclamos por parte de España, otro hecho internacional, de mayor envergadura, vino a cambiar el panorama político. El 21 de abril fuerzas militares norteamericanas desembarcaron en Veracruz. La ocupación de México por parte de Estados Unidos parecía un hecho. Tanto el gobierno de Huerta como el de Carranza rechazaron enérgicamente el atropello a la soberanía mexicana. Para evitar una guerra entre ambos países, los representantes diplomáticos en Washington de Argentina, Brasil y Chile, además del de España, ${ }^{24}$ se dieron a la tarea de

23 En el AHMAE, en los legajos H-2557, 2558 y 2559 pueden econtrarse numerosos ejemplos para el periodo 1909-1914.

24 Recordemos que España tenía que participar de alguna manera, pues estaba encargada en Washington de los asuntos mexicanos. Sin embargo, poco o nada se ha dicho sobre las gestiones españolas en los trabajos que estudian este conflicto. No sólo se ofreció la mediación de Alfonso XIII en caso de aceptarla los gobiernos de Estados Unidos y México, sino que también se pensó que las conferencias se realizaran en el buque español Carlos V. "Correspondencia de Riaño con el ministro de Estado", AHMAE: H-2 559. 
servir de mediadores. Sin que el arbitraje resultara un éxito, a final de cuentas la guerra no estalló, ni pudo Estados Unidos imponer sus condiciones a las facciones mexicanas en pugna, si bien Huerta acabó por renunciar a la presidencia y la revolución constitucionalista resultó vencedora.

Por su parte, el embajador español en Washington no descansaba en sus gestiones para ayudar a sus compatriotas en México a la vez que sugería a su gobierno la política a seguir en este caso. Así, por ejemplo, informó que Inglaterra estaba dispuesta a tomar la aduana de Tampico en caso de que se lesionaran sus propiedades petroleras fundándose en la doctrina, reconocida por Washington, "de que toda nación extranjera tiene el derecho de obtener por la fuerza el pago de justas deu- das contraídas por las repúblicas latinas, siempre que dicha acción no implique la adquisición permanente de territorio", y con el objeto de que se considerara si era prudente obrar en igual sentido para "obtener el pago del algodón y demás propiedades confiscadas $[\ldots]$ si sus reclamaciones no son reconocidas". ${ }^{25}$ Con respecto a dicho algodón, se iniciaron procesos judiciales ${ }^{26}$ en Estados Unidos con la

25 "Riaño al ministro de Estado, 23 de mayo de $1914^{\prime \prime}$, AHMAE: H-2559.

26 Riaño intentó que el gobierno norteame. ricano decomisara los efectos "robados" cuando éstos llegaran a Estados Unidos, pero dicho gobiemo se negaba -aun cuando las mercancías pertenecieran a estadunidenses-aduciendo no tener facultades para ello, a la vez que indicaba que sólo procedía que se presentara el asunto ante los tribunales. "Riaño al ministro de Estado, 11 de abril de 1914", AHMAE: H-2558.

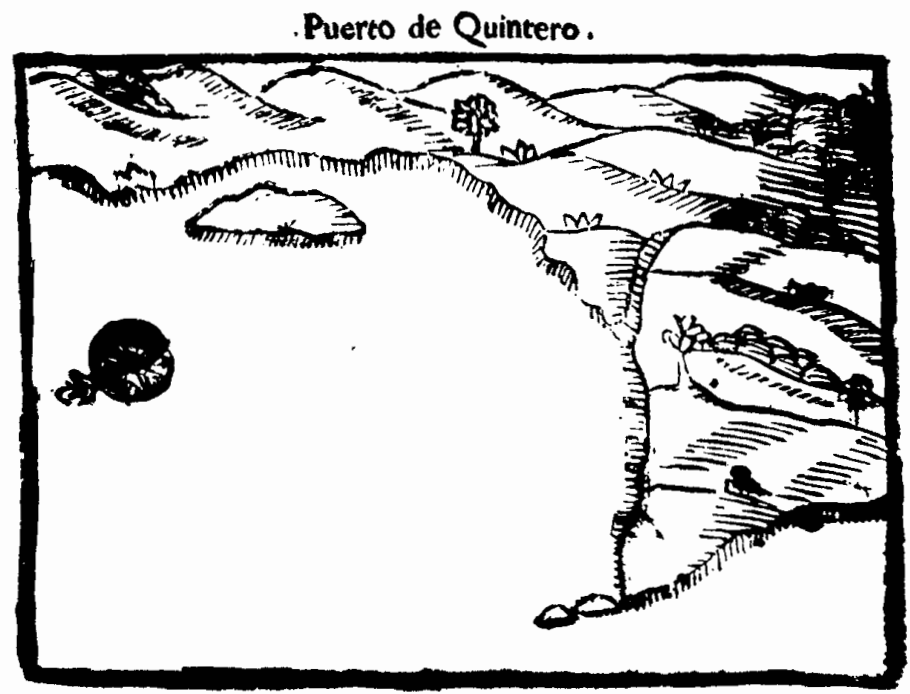


finalidad de que no pudiera ser vendido en ese país. Sin embargo, como se temía que pudiera embarcarse en Tampico, Riaño gestionó ante los representantes europeos en Washington que éstos tomaran cartas en el asunto. La sugerencia consistía en que se embargara "el algodón robado" para impedir que Villa, el "audaz bandolero, obtenga el fruto de su rapiña". Asimismo, comunicó los resultados de las gestiones norteamericanas en torno a las dificultades hispanas. George $\mathrm{Ca}$ rothers acordó con los constitucionalistas que se autorizara a los productores españoles a exportar su algodón, pagando 15.00 pesos oro por paca como impuesto de guerra, además del permiso para regresar a México y ocupar sus propiedades. También se estableció que una comisión de seis constitucionalistas, integrada por Alberto Madero, Alberto Pani, Adrián Aguirre Benavides, Carlos Argüello y E. R. Barrera -el otro nombre no se indica-, revisaría y determinaría lo conducente en los casos de los españoles que se sospechaba hubiesen participado en política; de no encontrárseles culpables, podrían volver a México y su algodón les sería devuelto. ${ }^{27}$

Desde Washington, Riaño trató de impedir que los revolucionarios obligaran a los españoles de Tampico a otorgar un préstamo de 500000 pesos. Al enterarse de que se había desistido de imponer a otros extranje-

27 "Riaño al ministro de Estado, 25 y 29 de mayo de 1914", AHMaE: H-2558. Carothers era agente confidencial de Estados Unidos ante Villa y realizó estos arreglos con "de la Garza", muy probablemente Lazaro de la Garza, hombre encargado de las finanzas del ejército de Villa. ros el mismo préstamo y de que a los españoles aún se les exigía una cuota de 135000 pesos, Riaño pidió al jefe del Departamento de Estado, James Bryan -quien todavía trataba de presionar al gobierno norteamericano para que influyera en México a favor de los españoles-, que fuese evitado dicho "despojo" así como la continua, prolongada $e$ injustificada persecución a sus compatriotas. Bryan ofreció atender la solicitud pero sin comprometerse a nada, no sin antes insistir en que el problema radicaba en que los españoles simpatizaban con las tropas del ejército federal. ${ }^{28}$ No obstante, y sin que sea posible precisar cómo se logró, el 20 de junio, en Torreón, Villa emitió un decreto en el que explicaba su conducta con relación a los españoles y permitía el regreso, con toda clase de garantías, de aquellos que no se hubieran mezclado directa ni indirectamente en política. En este documento, el general norteño señalaba que, al tomar Chihuahua, Torreón y otras poblaciones de La Laguna, había recibido pruebas de que la colonia española "en general" había participado en política "siempre en contra de los legítimos ideales del pueblo", e incluso tomado las armas para apoyar a Huerta; y que, debido a las condiciones de guerra, no podía admitir tal conducta, misma que le había obligado a decretar su expulsión, sin incluir en ella a sus familias. Sin embargo, Villa reconocía asimismo que esta medida había afectado a varios "inocentes, algunos de los cua-

28 "Riaño al ministro de Estado, 3 de junio de 1914", AHMAE: H-2558. 
les son útiles a la sociedad y al país en general", por lo que modificaba la medida inicial para así permitir que esos "inocentes" retornaran al país.

El desembarco norteamericano en territorio mexicano puso en alerta al gobierno español. Este esperaba de parte de las potencias del viejo mundo una definición al respecto y que pudieran ponerse de acuerdo para asumir una actitud semejante. El hecho de que no existiera "estado de guerra con México ni [el] bloque" fue pretexto suficiente para que no se declarara nada tocante al alarde militar en Veracruz, por más que se coincidiera en que Europa debía proteger a sus nacionales. ${ }^{29}$

La precaria situación de los espanoles expulsados, el hecho de que el puerto mexicano estuviese en manos de fuerzas militares norteamericanas y el avance revolucionario obligaron a que España se planteara la necesidad de una intervención en México. El 11 de mayo, el marqués de Lema telegrafió a Riaño indicándole que en la capital mexicana se temía una catástrofe para los españoles si Estados Unidos no intervenian militarmente, y le ordenaba que expresara a Bryan la responsabilidad que contraería ese país si no impedía que las "hordas revolucionarias" repitieran los hechos de Chihuahua y Torreón. Asimismo consultó, con sus representantes en México y en Estados Unidos, la pertinencia de que España solicitara formalmente que el gobierno norteamericano interviniera por un tiempo determinado en México

29 "Correpondencia del ministro de Estado con los embajadores españoles en Londres, París, Berlín y Roma, 24 al 27 de abril de 1914", AHMAE: H-2559. para proteger a los extranjeros. El diplomático en Estados Unidos hizo notar que la cancillería norteamericana no había tenido noticia de otras expulsiones y que ésta se había comprome. tido a proteger a los españoles y a sus propiedades en la medida de lo posible. Asimismo, observó que Bryan no consideraba, "en la actualidad, oportuna o necesaria la intervención en México". Riaño, por el contrario, creía, al igual que Cólogan, que la ocupación de México por parte de Estados Unidos era necesaria y conveniente. Cauteloso, sin embargo, apreciaba que era un enorme riesgo "apartarse de la actitud observada por los pueblos europeos", ya que ninguna nación de Europa había creído pertinente solicitar intervención alguna, "dejando a los Estados Unidos la responsabilidad total de tal acto". 30

Pese a que todo lo que ocurría en México era bastante complejo y el panorama escaso $e$ incierto al no saberse el derrotero definitivo de la revolución, empezaban ya a percibirse como irreductibles las diferencias entre los lideres revolucionarios. Tal vez por eso mismo España comenzó a actuar de inmediato con el objetivo fundamental de proteger a sus nacionales en México y sus intereses. De modo que decidió enviar un agente confidencial.

La misión de Walls y Merino sólo tenía dos propósitos: establecer contacto con Carranza y con Villa, a fin de limar asperezas para lograr "un

30 "Riaño al ministro de Estado, 12 de mayo de 1914", AHMAE: H-2558; "Ministro de Estado a Riaño, 11 de mayo" y "Riaño al ministro de Estado, 13 de mayo", AHMAE: H-2559. 
cambio favorable en los sentimientos que hasta ahora han venido abrigando los revolucionarios hacia el elemento español en México", y facilitar, así, las actividades del nuevo representante de España. Esto por una parte; por la otra, pretendía aconsejar a la colonia española con el fin de que afrontara adecuadamente su situación. Riaño aconsejó a Walls que se esforzara por crear una atmósfera más favorable a los españoles para así obtener un trato más justo, limitándose a arreglar los asuntos pendientes ya iniciados y de fácil desenlace, "sin entrar en la cuestión de reclamaciones atrasadas, cuyo examen ahora, aparte de que en estos momentos en que aún no se ha constituido el gobierno, a poco conduciría, podría perjudicar su éxito cuando llegara el momento conveniente de presentarlas".31

\section{WALLS EN MÉXICO}

\section{Las negociaciones}

Desde el momento en que Walls se presentó telegráficamente a Fabela para solicitar audiencia con él y con Carranza, el español hizo hincapié en que su nombramiento como agente confidencial respondía a los ofrecimientos del Primer Jefe en el sentido de que recibiría las representaciones que se le hicieran por medio de los agentes extranjeros designados a entenderse con las autoridades constitucionalistas; por tal motivo apro-

31 "Riaño al ministro de Estado, 16 de julio de 1914", AHMAE: H-2559. vechó ese primer comunicado para pedir que se investigaran los ataques a españoles en Zacatecas y se "aparejara la reparación que fuera de justicia". 32

También, desde el momento en que llegó a la frontera fijó la táctica a seguir para cumplir su cometido, misma que practicó en todas las etapas de su viaje. Además de establecer contacto con los responsables de la política exterior de la revolución, de realizar todas las gestiones necesarias y de entrevistarse con la colonia española en cada poblado, Walls decidió no hacer recriminaciones de ninguna especie que los atropellos en contra de los españoles hubiesen motivado. Otra de sus intenciones fue reunirse y entrevistarse con todos aquellos personajes prominentes que pudieran influir a fin de lograr los mejores resultados de su encargo. Así, se acercó a cónsules y a agentes norteamericanos, a gobernadores, jefes militares del ejército revolucionario y a hombres relevantes con la finalidad de intimar con los más convenientes pero sin entrar en disputa con los otros, pues "en los países se consigue más por amistad que por la fuerza de la justicia o de la equidad".33 No se le ocultaba a Walls que sus observaciones eran de vital importancia para cada paso que debía dar, pero la cautela con que actuaba no impidió que su actuación fuera enérgica y decidida cuando debía serlo.

Asimismo, muy pronto, al permi-

32 "Telegrama Walls a Fabela desde El Paso [probablemente 20 de julio]", reproducido en el "Informe núm. 1 del 22 de julio de 1914". AHMAE: H-2559.

33 "Informe núm. 5, 4 de agosto de 1914", AHMAE: H-2559. 
tírsele avanzar en territorio mexicano para encontrarse con el líder del movimiento revolucionario, bosquejó los planteamientos que se le podían hacer para solucionar los problemas que aquejaban a los españoles. Dichos planteamientos eran los siguientes:

1. Respetar el derecho de extranjería en la persona y propiedades de los hispanos residentes en la zona dominada por el constitucionalismo;

2. Atender las reclamaciones justas presentadas en tiempo oportuno por el gobierno de España por daños y perjuicios causados por la revolución;

3. Admisión franca de los españoles expulsados de algunas regiones y devolución de los bienes y propiedades confiscados.

En las negociaciones, España ofrecería a cambio:
No apoyar las reclamaciones de sus nacionales contra quienes existieran pruebas irrefutables de haber participado directa y activamente en los asuntos políticos de México, a reserva de que éstos pudieran presentar pruebas de descargo ante los tribunales competentes y en presencia de un representante del gobierno español. ${ }^{34}$

Al aceptar que algunos de sus compatriotas podian haber intervenido en los asuntos internos de México, Walls hacía frente a uno de los reproches que el constitucionalismo formulaba a los españoles. A la vez, admitía tácitamente -al no hacer ningún reparo al respecto- que se castigara con la expulsión y aun con la confiscación de sus bienes a todos aquellos que se

34 Ibid.

\section{Puerto de Coquinbo.}

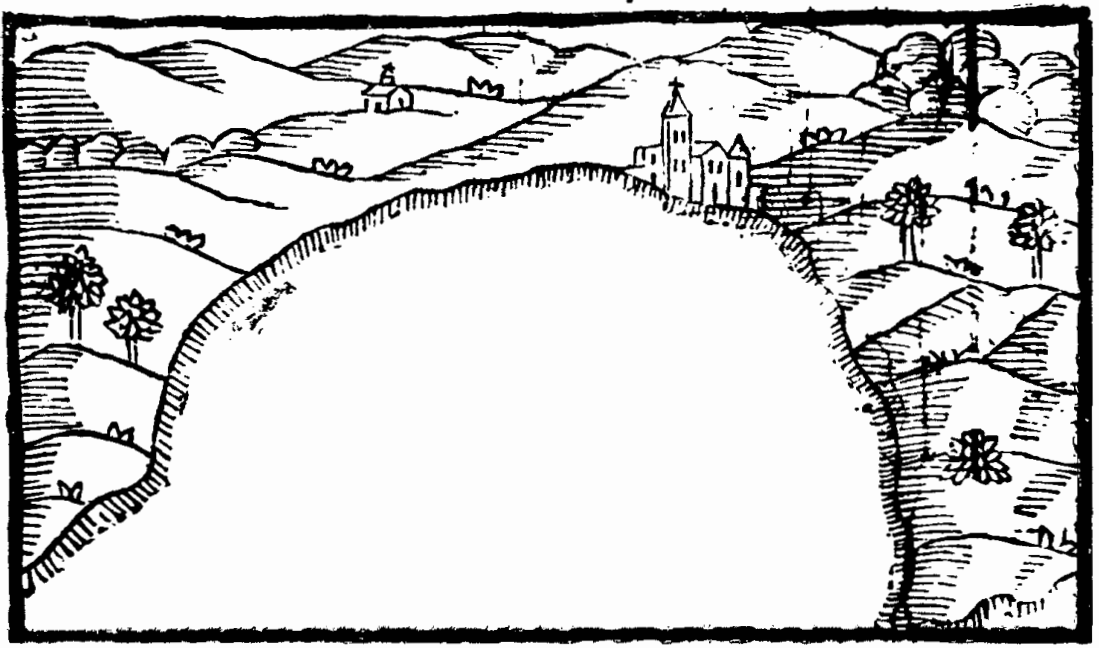


les probara haber realizado actividades políticas. Asimismo, en sus propuestas se incluían dos elementos importantes: la oportunidad de las reclamaciones y el que éstas fueran justas. A pesar de la ambigüedad de los términos, el señalamiento permitiría discutir y negociar cada caso al reconocer que podrían presentarse algunos que no reunieran esta exigencia.

El 30 de julio Walls pudo entrevistarse con Venustiano Carranza en Monterrey. Ahí le dio a conocer el objetivo de su presencia en el país: normalizar la situación de los españoles en México, "tan grave y severamente perjudicados". El Primer Jefe hizo notar que éstos se habían opuesto al movimiento que él encabezaba y que tal intromisión debía ser castigada, aunque reconoció que bien pudo haberse sancionado a inocentes. A continuación, Carranza autorizó que Walls tratara con Fabela los asuntos pendientes entre embos países. Este permiso le venía de perlas a Walls, ya que consideraba que Fabela veía con simpatía a España, pues sabía que desde la revolución maderista se había interesado en detener los vejámenes a los españoles. Sin embargo, decidió posponer la discusión de aquéllos por parecerle inoportuno tratarlos en el momento mismo en que los delegados de Francisco S. Carbajal -presidente interino que sustituyó a Huerta-conferenciaban con los constitucionalistas. ${ }^{35}$ Pero no por ello cejó en sus intentos de llegar a satisfactorios acuerdos con las autoridades locales de las ciudades que iba visitando, una vez que decidió seguir a Carranza

35 "Informe núm. 4, I de agosto de 1914", AHMAE: H-2559. en su avance hasta la ciudad de México y éste aceptó que los acompañara.

Walls era consciente de que tenía que establecer vínculos tanto con Carranza como con Villa, pero decidió seguir al primero porque era en la capital de la república "donde hay más intereses por el momento que defender". ${ }^{36}$ También percibía nítidamente lo riesgosa que resultaba esta decisión, dado que podía causar el descontento de Carranza, pues la posibilidad de un rompimiento entre éste y Villa estaba siempre presente.

De tiempo atrás, Riaño venía dando cuenta al Ministerio de Estado acerca de los conflictos entre ambos. Walls no los ignoraba ${ }^{37}$ y los atribuía a la antipatía que Villa sentía por Carranza. Opinaba que, como el Centauro del Norte no tenía posibilidades de acceder a la presidencia, se había propuesto detener a Carranza. Walls hacía notar que se temía que aquél, en el caso de una ruptura, atrajera al

36 "Informe núm. 9, 15 de agosto de 1914", AHMAE: H-2559.

$37 \mathrm{Si}$ bien podía ser que no conociera los acuerdos secretos del Pacto de Torreón, celebrado el 8 de julio de ese mismo año entre los grupos villista y carrancista, era imposible que no tuviera noticia de los públicos. Entre los primeros se contaban el que Carranza limitaría su autoridad a los asuntos civiles y diplomáticos; que Felipe Ángeles dirigiría el ejército constitucionalista, y que Villa y su columna alcanzarian, respectivamente, igual rango que $\mathrm{Pa}$ blo González y Álvaro Obregón y las fuerzas que encabezaban. En cambio, púbicamente se aceptó que se crearía una junta de gobiemo consultiva, que Carranza se encargaría interinamente de la presidencia de la república y que se celebraría una convención de delega. dos militares después de ocuparse la ciudad de México para resolver lo que debía hacerse a continuación. Ulloa, Revolucion, 1979, p. 19. 
ejército federal a su bando, pues Carranza había rechazado cualquier arreglo con Carbajal y se decía que Villa había ofrecido reconocer los grados de quienes se unieran a su contingente. Personalmente, Walls sostenía, con mucho tino, que las diferencias entre los dos líderes eran muy hondas y, en consecuencia, difíciles de subsanar; además, que la decisión de Carranza de avanzar solo a la ciudad de México habría de provocar "al fin una franca ruptura". Por ello le preocupaba no alcanzar el buen éxito que deseaba en su gestión y, así, quedar "en medio" de las dos facciones, lamentándose de no haberla iniciado tiempo atrás, cuando Riaño la propuso, y que ésta no hubiera quedado en manos de varios agentes confidenciales. ${ }^{38}$

Walls percibía que el orgullo de Villa tampoco admitiría ocupar la capital con Carranza, pues "no ha de entrar de rabo en la comitiva", no obstante que no dejaba de afirmarse que los seguía de cerca su ejército. Asimismo, le parecía que Carranza se obstinaba en no reconocer la importancia de su rival debido a esa terquedad que lo caracterizaba, por lo que avizoraba "gravísimas dificultades muy pronto". 39 Esta incertidumbre ante los caminos que habría de seguir la revolución, obliga. ban a Walls a no perder de vista lo importante, para su embajada, de una acción rápida y el traslado al campo villista antes de que pudiera tener efecto la escisión.

38 "Informes núm. 1, 2, 4 y 8, del 22 y 23 de julio, y 1 y 8 de agosto de 1914", AHMAE: H-2559.

39 "Informe núm. 10, 16 de agosto de 1914", AHMAE: H-2559.
Walls aprovechó su viaje de Monterrey a la ciudad de México para tratar con Fabela los asuntos para él más relevantes de su cometido. Viaje que, por un lado, se había realizado de manera apresurada e inicialmente en pésimas condiciones, y que, por otro, ofrecía oportunidades excepcionales pues permitía la convivencia con hombres prominentes del constitucionalismo, miembros del gabinete y jefes militares y, desde San Luis Potosí, con el propio Carranza. La circunstancia era, de hecho, privilegiada para un diplomático, si bien dos norteamericanos la compartían: John R. Silliman y Sherbouene Hopckins, ${ }^{40}$ y colocaba a España en una posición especial a diferencia de las otras naciones que, habiendo reconocido a Huerta, aún no acreditaban agentes ante la revolución. Así, como parte de la comitiva carrancista, le tocó presenciar en Teoloyucan la visita de los representantes diplomáticos a Carranza ${ }^{41}$ que solicitaban garantías para los extranjeros al ser ocupada la capital y el rechazo a la representación de Sir Lyonel Carden, ministro inglés, por no considerársele

${ }^{40}$ De acuerdo con Katz, Guerra, 1982, Hopkins era un agente de los intereses económicos, muy influyente en Estados Unidos, que se decía era organizador de revoluciones latinoamericanas promovidas y financiadas por esos intereses. Se sabe que Carranza utilizó los servicios de este hombre para representarlo en Estados Unidos.

41 A Teoloyucan llegaron Juan Manuel Cardoso de Oliveira, ministro del Brasil; el señor Ayguesparsse, engargado de negocios de Francia; el ministro guatemalteco, Juan Ortega y el propio Carden. De acuerdo con Fabela, Historia, 1985 , vol. I, pp. 265-266, era evidente que Carden era enemigo de la revolución por lo que procedio, por 6rdenes de Carranza, a ser expulsado del país en cuanto la capital fue ocupada. 
grato debido a que, a juicio del carrancismo, compartía responsabilidades en la caída del gobierno maderista.

Con objeto de tranquilizar a la colonia española en la ciudad de México y de anticiparse a los problemas que pudieran surgir por el arribo de los revolucionarios a la capital, Walls solicitó permiso para adelantarse a la columna del Primer Jefe. Autorizado para ello, partió con Silliman y gozó de tocla clase de facilidades. Ya en la capital, se presentó de inmediato ante las autoridades de la ciudad, Álvaro Obregón y Francisco Cosío Robelo, a quienes ya conocía. Walls temía que los asuntos que a él le interesaban pudieran retrasarse, ya que lo que importaba en esos momentos a los revolucionarios era constituir el gobierno en la ciudad de México, lo cual no era fácil debido a que, según percibía Walls, además de la pugna entre Villa y Carranza, existían diferencias entre las autoridades carrancistas -Obregón y Alfredo Robles Domínguez, o las de éste con Cosío Robelo-, así como dificultades monetarias que podían conducir al cierre del comercio. Por ello, no retrasó más sus gestiones.

El día 17 de agosto, en Tlanepantla, Walls entregó formalmente a Fabela las reclamaciones españolas pendientes, puesto que otras se habían resuelto durante el viaje. Creyó también oportuno intentar un acercamiento entre la colonia española y Carranza presentándole una comisión -que resultó la primera comisión de extranjeros que fue a saludarlo- integrada por Enrique Zavala, presidente del Casino Español, Manuel Rivera Collada, presidente del Descuento Español y del Banco Oriental de Puebla, y Adolfo Prieto.

La posición de los españoles empezaba a cambiar, o cuando menos a mejorar. En efecto, como el gobierno carrancista no reconocía más que a aquellos diplomáticos acreditados ante él mismo, resolvió invitar solamente a Silliman, Walls y a Cardoso a la recepción organizada en honor de Carranza a su entrada a la capital. El representante brasileño, Cardoso, se negó a asistir porque el cuerpo diplomático en pleno no había sido convocado. Empezaban a chocar dos maneras de apreciar las relaciones diplomáticas entre las naciones, una más tradicional que la otra, en la que las formas eran de suma importancia. Walls mismo señalaba que los revolucionarios mexicanos habían "borrado de una vez todo protocolo [pues] están dispuestos a hacer su voluntad" y creía que éstos, finalmente, tendrían que modificar sus planes, pero "no sin graves disgustos de los diplomáticos, sobre todo los que no están habituados a tratar con los países antiprotocolistas". 42

Pese a esta postura, que parecía no obstante ofrecer garantías, Walls no descansó en su búsqueda incesante de una actitud favorable hacia sus compatriotas -pues temía que las cosas cam. biaran en cuanto se saciaran las rencillas, odios y envidias en contra de los mismos mexicanos. Así, logró que Cosío Robelo le asegurara que no tenía órdenes de proceder contra ningún español. Pero no sólo eso, sino que

42 "Informe núm. 12, 23 de agosto de 1914", AHMAE: H-2559. 
obtuvo su ofrecimiento de que, en caso de que surgieran algunas, se lo notificara Walls con anticipación para que tomara las medidas que creyera convenientes. ${ }^{43}$

El cierre sorpresivo del Casino Español, a mano armada, durante la noche del 26 de agosto, llevó a Walls a acudir nuevamente a Isidro Fabela. Mediante esta intervención el comandante militar de la plaza autorizó que el local se reabriera, advirtiendo que de noche se vigilaría para evitar que alguien ajeno a la sociedad se ocultara; además, liberó a un español preso. Pero así como los mexicanos no le inspiraban confianza por estos cambios en sus decisiones, tampoco los españoles se la ofrecían, por lo que aconsejó que el casino se cerrara para evitar que una vez reunidos sus paisanos, aquéllos fueran a dar rienda suelta a su disgusto.

Walls daba cuenta de que sus comunicaciones con Fabela habían sido siempre contestadas en términos satisfactorios y de acuerdo con las órdenes de Carranza al respecto; sin embargo, no confiaba en que se cumplieran al pie de la letra en todas partes, pues "a Carranza se le ha desobedecido y se le seguirá desobedeciendo sin que él se preocupe gran cosa con tal de que le sigan llamando Primer Jefe o presidente". $\$ 4$

13 "Informe núm. 13, 25 de agosto de 1914", AHMAE: H-2559.

14 "Informe núm. 14, 27 de agosto de 1914", AHMAE: H-2555. Como puede verse, la opinión respecto a Carranza no era del todo favorabie. Más adelante podremos observar cómo parece inclinarse más por Villa, y esperar más de él, olvidando que las acciones más severas contra

\section{Con la colonia española}

Como dijimos anteriormente, uno de los objetivos de la misión de Walls era acercarse a los residentes españoles en México y orientarlos. A lo largo de su viaje, trató de hacerlo en la medida que la rapidez del mismo se lo permitía. Esto, por ejemplo, fue factible en Monterrey, pero ahí, prácticamente, la colonia no había sufrido percance alguno, incluso hubo la oportunidad de que ésta le ofreciera un desayuno al que asistieron el gobernador, Antonio I. Villarreal, y Luis Cabrera. ${ }^{45}$ En otros lugares, como San Luis Potosí, se conformó con conocer los motivos de queja para hacer las reclamaciones pertinentes. Ya en la ciudad de México -y recordemos que la llegada de Walls fue anterior a la de Carranza- le fue imposible al diplomático basarse en el trabajo o en los informes y observaciones del encargado de negocios de la legación española, el conde de Galarza, pues éste se encontraba seriamente enfermo. Así que decidió entrevistarse -como muchos de sus compatriotas se lo habían aconsejado- con Adolfo Prieto, "español de larga residencia; joven; inteligente, ilustrado, útil", y en su compañía se dirigió al Casino Español para comunicarle a Zavala, presidente de la organización, sus deseos de reunirse en ese lugar con los miembros de la colonia española y dar-

la colonia española partieron de éste, que era, precisamente, uno de los militares que no obedecía a Carranza.

45 "Informe núm. 6, 6 de agosto de 1914", AHMAE: H.2559. 


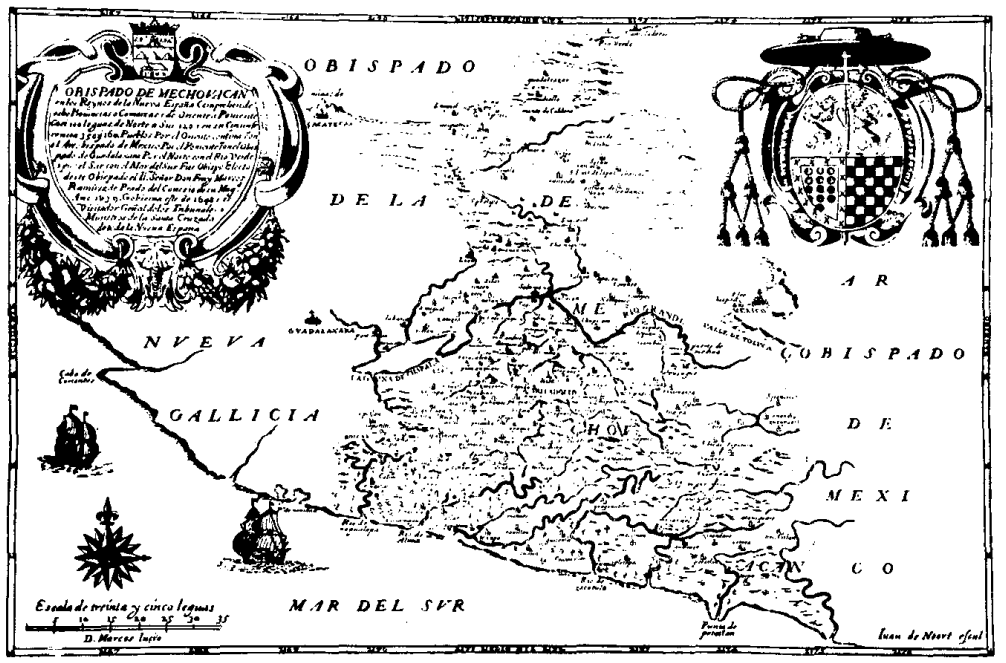

les a conocer sus impresiones sobre el nuevo gobierno. ${ }^{46}$

Walls sabía perfectamente cuál era el motivo que podía desencadenar la represión de los revolucionarios hacia los españoles. Por ello, en la junta que tuvo en el salón de actos de la institución, les hizo notar a sus paisanos que abrigaba la esperanza de que ningún miembro de la colonia hubiera tomado partido en los problemas de México, según "les imponía su calidad de extranjeros", y pidió que si alguno lo había hecho, apoyando a los sublevados de la Ciudadela o a Huerta, que ése asumiera su responsabilidad y no hiciera partícipe de ella a aquellos otros que no se habían com. prometido. Por tal motivo, solicitaba

46 "Informe núm. 10, 16 de agosto de 1914", AHMAE: H-2559. a los inculpados que se alejaran de México a la brevedad posible, toda vez que el nuevo gobierno "venía animado de unos procedimientos e ideas radicalísimos". 47

Sin decir cuántos ni quiénes, el agente informó que "varios" que se sabían comprometidos, le confiaron

47 Al representante español le era imposible comprender los objetivos o las formas de actuar de la revolución y cabe agregar que jamás se preocupo por acercarse al programa de los constitucionalistas. Walls afirmó también: "Esta gente viene inspirada en radicalismos desconocidos en la práctica." En realidad, no podía definir o entender esa práctica, y ni siquiera lo intentaba. Así, si bien califico a Villarreal de un radical libertario, no cayó en la tentación de calificar de la misma manera al movimiento, tal vez porque, como español, conocía más de cerca el anarquismo y reconocía que la revolución mexicana no iba por esos derroteros. 
su situación y acordaron que algunos salieran hacia Veracruz al día siguiente y otros hicieran lo mismo, tan pronto arreglaran asuntos urgentes. De esta manera, Walls protegía a sus compatriotas a la vez que podía mantener su ofrecimiento al gobierno carrancista de aceptar la expulsión de los que hubieran participado en la política mexicana.

Personalmente, Walls consideraba que muchos de sus paisanos eran unos testarudos, y que la ignorancia de "la generalidad" así como la falta de dirección eran las causas de los problemas entre ellos y los constitucionalistas. Había sido informado de que, cuando los miembros de la colonia ofrecían apoyo, recursos, mercancías, etcétera, el ejército sólo tomaba lo que necesitaba sin perjudicarlos, y les entregaba los recibos correspondientes. En cambio, otros habian tratado de batir a los revolucionarios y luego, ya derrotados, se negaban "a entregar por las buenas lo que no podían evitar por las malas". En tales circunstancias, aquellos que se les enfrentaron, al no escapar, los revolucionarios los fusilaron, les robaron cuanto tenían y arrasaron sus propiedades.

A Walls no dejaba de asombrarle esta actitud asumida por algunos y sostenía: "Oponerse abiertamente a una avalancha es decidirse uno a perecer con ella." Esperaba una respuesta por parte de los españoles demasiado prudente y conformista con lo que ocurría; bien se veía que no eran suyas las propiedades. Cómo esperar que nadie reaccionara ante el temor a lo desconocido -pues eso era precisamente la revolución: una fuerza impredecible- y que todos estuvieran dispuestos a perder resignadamente sus bienes -pues, aunque no fuera del todo cierto, eso parecía implicar el violento proceso que se vivía en México-, bienes que, por otro lado, en muchos casos había costado años de esfuerzo conseguir.

La desunión de los inmigrantes era otra de las dificultades que en opinión de Walls debía ser vencida, pues "ni aun en momentos tan críticos como los presentes tienen el buen sentido de comportarse con cordura". ${ }^{48}$

Los temores de los extranjeros hacia todas las medidas revolucionarias resultaban en ocasiones excesivos, o bien, reflejaban el deseo de éstos de mantener una situación privilegiada frente a los mexicanos. Gran alarma causó entre ellos el bando de Cosío Robelo que ordenaba la entrega de todas las armas y municiones en manos de civiles, bajo pena de muerte para quien no lo hiciera. Los extranjeros argumentaban que era una medida que podía aprovecharse como una trampa para perjudicar a quien se quisiera. Para tratar este asunto, el agente se entrevistó, en compañía de Silliman, con

48 "Informes núm. 10 y 12,16 y 23 de agosto de 1914", AHMaE: H-2559. Hay que destacar el hecho de que para nosotros todos ellos eran españoles, pero internamente se hallaban profundamente divididos por regionalismos, hecho evidente en las agrupaciones que los aglutinaban: Orfeón Catalán, Centro Asturiano, etcétera. Walls informaba que también había tenido que intervenir en rencillas entre compatriotas, por ejemplo en el caso de un español que fue herido por otro, al que se encarcelo. Walls negocio con ambos, hasta convencerlos, para lograr que se excarcelara al prisionero y se le dieran sarisfac. ciones al herido. 
Robles Dominguez, "que es de lo más culto que tiene la revolución" y quien, al decir de Walls, se encontraba molesto por esta orden y había puesto a Carranza como condición que se revocara para continuar al frente del gobierno del Distrito Federal. 49

Walls no olvidaba que no sólo debía atender a las quejas, sino también aconsejar a sus compatriotas, y así lo hacía en efecto. Por considerarlo conveniente para el bienestar de la colonia, insistió ante ellos en que atendieran el bando de Cosío y entregaran sus armas, y no sólo que acataran ese bando sino todas las disposiciones de los constitucionalistas. Parece ser que para Walls el bienestar de los españoles en México y la defensa de sus intereses radicaba, en buena medida, en esa obediencia. ${ }^{50}$

Walls pedía, e imponía, la prudencia de los españoles ante las circunstancias extraordinarias que se vivían. Por ello, para evitar que los sentimientos antiespañoles -que particularmente afloraban en el mes de septiembre- se hicieran manifiestos, promovió la suspensión de los festejos de La Covadonga del 8 de septiembre, tradicionales entre los inmigrantes, y otras actividades preparadas por los catalanes. Walls temía que una reunión de españoles provocara sentimientos hostiles y diera pie a algún incidente desagradable. El propio Walls afirmaba que su actividad entre los inmigrantes españoles buscaba no sólo "inspirar en la colonia ánimo y confianza",

49 "Informe núm. 11, 19 de agosto de 1914", AHMAE: H-2559.

so "Informe núm. 18, 1 de septiembre de 1914", AHMAE: H-2559. sino aconsejarles la "mesura de que no han dado pruebas anteriormente". 51

Al parecer, la colonia española estaba tan satisfecha con la actividad desplegada por Walls, que le pidió que se quedara en la ciudad, cuando menos hasta el 16 de septiembre, fecha propicia para dar rienda suelta a la animadversión hacia los españoles. Y él mismo, complacido con su trabajo, informaba que los abusos contra extranjeros no habían desaparecido, pero no se habían ejecutado más en contra de sus compatriotas, por lo que no había tenido que presentar ninguna nueva reclamación al gobierno mexicano, en tanto que los representantes de Francia, Italia y Estados Unidos sí lo habían hecho. 52

Pero las buenas noticias de la ciudad de México no correspondían a lo que ocurría todavía en otras partes. Por ello, antes de abandonar la capital quiso atar todos los cabos sueltos -de los que tenía cuenta-y agotar las posibilidades de su misión para ayudar a sus paisanos. Respecto de las monjas teresianas y los sacerdotes españoles presos en la zona de Torreón, prefirió no actuar directamente y acudió al padre Paredes, encargado de los asuntos eclesiáticos en México, para lograr su excarcelación, lo cual logró el sacerdote en sus gestiones con Carranza. Para atender a los problemas surgidos en San Luis Potosí, sugería que, además de que ya se hubieran tratado con el Primer Jefe, se encomendaran al cónsul norteamericano para

S1 "Informe núm. 12, 23 de agosto de 1914", AHMAE: H-2559.

52 "Informe núm. 18, 1 de septiembre de 1914", AHMAE: H-2559. 
que éste los presentara al gobernador, Eulalio Gutiérrez, por si -siempre desconfiado y observador de lo que ocurría entre los jefes mexicanos- éste se negaba a acatar las órdenes del centro. Como evidencia de la tenacidad de su gestión, también encargó la misma tarea al doctor Rafael Cepeda, quien iba como comisionado oficial al estado, no obstante que ya se le había notificado que se habían dado las órdenes respectivas desde México para clar garantías a los españoles en la entidad, y de que Silliman le había asegurado que el Departamento de Estado ya había tomado cartas en el asunto. Lo propio hizo con Villarreal, que se dirigía a Nuevo León, respecto a la libertad de un tal Samohano, preso en Monterrey, obteniendo de su parte el ofrecimiento de liberarlo. ${ }^{53}$

\section{En busca de Villa}

Apercibido de las dificultades existentes entre los revolucionarios y de que era imprescindible dirigirse al territorio villista, se puso en contacto en la propia ciudad de México con los agentes de Villa Carlos Martínez y Martín Luis Guzmán, a fin de lograr su propósito. Así, se enteró de que el jefe norteño había enviado emisarios ante Zapata y que, una vez que éstos acusaron a Carranza de traidor y pronosticaron que sería un tirano, Zapata y Villa se propusieron unirse para derrotarlo y "hacer la felicidad

53 "Informe núm. 19, 2 de septiembre de 1914", AHMAE: H-2559. de los mexicanos". ${ }^{54}$ Si bien Walls lo veía todo oscuro como para conjeturar o predecir algo, creía que el intento de Obregón por resolver los conflictos con Villa podía tener buen éxito si aquél se ofrecía a realizar la convención militar, debido a la popularidad de ambos generales. En cambio, respecto a la embajada de Villarreal y Cabrera, representantes carrancistas ante Zapata, no pudo más que augurar que fracasaría, como en efecto ocurrió. 55

Posteriormente, a través de su relación con Martínez y Guzmán, confirmó su idea de que no había arreglo posible entre el Primer Jefe y el jefe de la División del Norte, no obstante que la prensa afirmaba lo contrario. Por ello, no pudo permanecer más tiempo en la ciudad de México, siquiera hasta que pasaran las fiestas patrias, sobre todo porque consideraba que sus propósitos se habían cumplido en este lugar, es decir que los constitucionalistas no abusaran de los españoles residentes en la capital. Con la finalidad de que el gobierno de Carranza no juzgara su salida como precipitada o motivada por otras razones susceptibles de una mala interpretación y ello tuviera consecuencias en la colonia española, Walls había tenido el cuidado de difundir que le era imprescindible visitar Torreón y Chihuahua para informar a su gobierno

54 "Informe núm. 13, 25 de agosto de 1914 ", AHMAE: H-2559.

55 Ibid. La comisión incluía también a Juan Sarabia. El 5 de septiembre concluyeron las pláticas para llegar a un acuerdo, pues ninguno de los dos líderes aceptaba las condiciones del otro. 
acerca de los sobresaltos e inquietudes de sus paisanos en aquellas regiones. Sin embargo, comprendía que había sido una imprudencia política que una sola persona se ocupara del doble cometido y sólo deseaba que Villa no censurara su actividad con los constitucionalistas, ahora que queria acercarse "al sol que más calienta". Si bien cauteloso, no quería tampoco "significarse con personas que Dios sabe el camino que lleven dentro de pocas semanas". 56

En los informes puede constatarse una cierta inclinación de Walls hacia Vi1la. Se insiste en su fuerza y en su superioridad militar. Contradictoriamente, no parecía recordar o percibir que las

56 "Informe núm. 17, 29 de agosto de 1914", AHMUE: H-2559. más graves disputas por lesiones a los españoles en México se habían registrado en la zona villista. Asimismo, perdía de vista que la actitud más o menos complaciente de Carranza con él y sus compatriotas -que modificaba radicalmente las expectativas al respecto y que contrastaba abiertamente con el trato dado al representante ingléshabría sido totalmente diferente si se hubieran enviado dos agentes $o$, siquiera, si él hubiera acudido primero a entrevistarse con Villa. Era como si los considerara a ambos como jefes de la misma categoría, ante los que se tenían que realizar actividades semejantes, olvidando definitivamente que Carranza jamás había atendido las representaciones hechas ante sus subalternos y que había declarado enfáti-

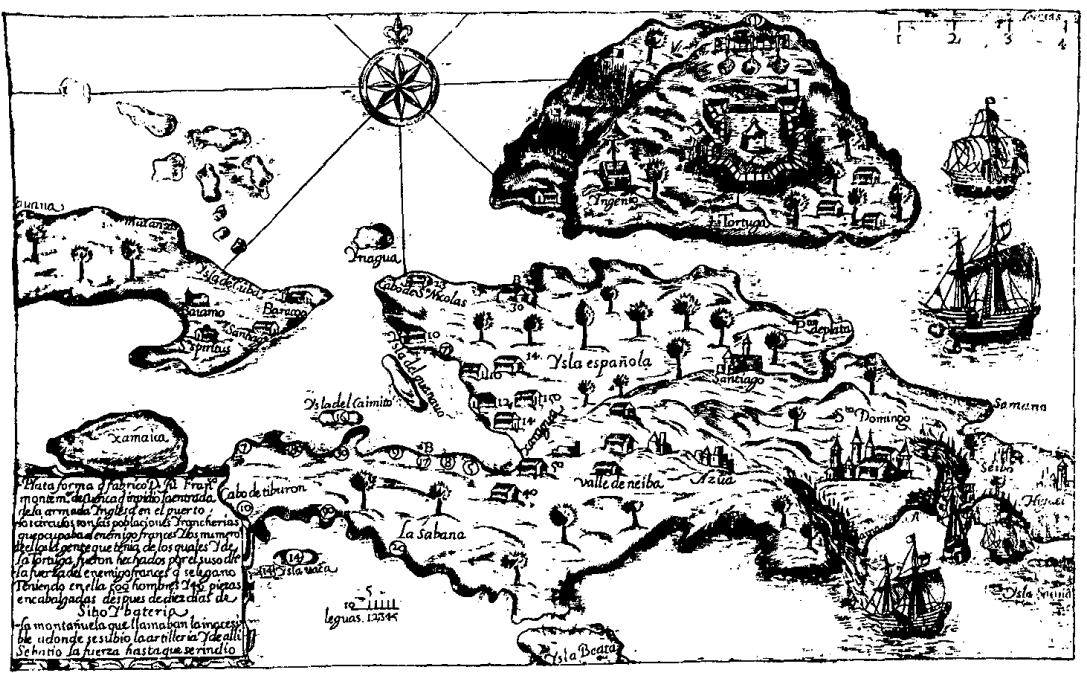


camente que nunca lo haría. También vale la pena señalar que Walls no sugirió o hizo ver la necesidad de dirigirse a Zapata en el mismo sentido. Parecía ignorar por completo que los españoles de la zona de Puebla eran constantemente amagados, tanto en sus propiedades industriales como en las agrícolas, a sabiendas de que los zapatistas no actuaban bajo la bandera constitucionalista. ${ }^{57}$

Así, debido a su especial interés por entrevistarse con Villa, Walls realizó cuanto trámite estuvo a su alcance para partir al norte, lo que pudo hacer el 5 de septiembre en la noche, a causa de las serias dificultades que sufría el transporte ferrocarrilero, y sólo después de encargar que se resolvieran algunos asuntos pendientes, $y$ de clespedirse de Carranza, Fabela, Cabrera y Fernando Iglesias Calderón.

El viaje al norte fue largo y pesado: duró cinco días. Nuevamente, Walls siguió la táctica que tan buenos resultados había dado con los carrancistas: localizar personas clave, entrevistarse con ellas, no recriminar, etcétera. En el primer día se acercó a Raúl Madero y a Luis Aguirre Benavides -secretario de Pancho Villa-, entre otros, sorprendiéndole que el general le hubiera dispuesto hospedaje y me-

\footnotetext{
57 Para mayor información sobre los ataques a españoles en Puebla véase González Loscertales, "Empresariado", s.a., y "Colonia", 1977. Desafortunadamente Gamboa Ojeda, Empresarios, 1985, no dice nada al respecto, apuntando tan solo que, a partir de 1913, la industria textilera poblana empezó a resentir la falta de suministro del algodón de la región lagunera, industria que, en su mayor parte, estaba en manos de españoles.
}

dio de transporte. Asimismo, logró ser presentado el día de su arribo con el jefe de la División del Norte.

Durante la conferencia, Villa agradeció que el gobierno español le enviara un emisario y justificó que se hubiera castigado a los españoles en el hecho de que éstos tomaron partido en los problemas domésticos, aunque también lamentó los excesos cometidos contra los inocentes. El general agregó que a aquellos que no habían participado en los conflictos internos ya se les había hecho volver y gozaban de toda clase de garantías. ${ }^{58}$ Por su parte, Walls lamentó que españoles mal aconsejados e ignorantes hubieran olvidado su calidad de extranjeros, inmiscuyéndose en política, $y$ hubieran "hecho culpable a una colonia honrada y laboriosa que había hecho más por el engrandecimiento de México que por el bienestar de su misma patria". Además, destacó que esperaba que la buena voluntad y la cordura se restablecieran a la mayor brevedad posible.

Al fijar lo que Walls calificaba como "los flacos", es decir las debilidades de Villa, decidió atacar por ahí, elogiando constantemente ambos puntos: por un lado, su "talento natural", y por otro, la superioridad de sus tropas. Alabanzas que, además, no le costaba mucho esfuerzo prodigar, debido a que lo reconocía como evidente. ${ }^{59}$

58 "Informe núm. 20, 10 de septiembre de 1914", AHMAE: H-2559.

59 "Informe núm. 21, 12 de septiembre de 1914", AhmaE: H-2559. Debido a ese talento de Villa, le parece a Walis que el general había modificado su actitud primera, "que era su natural", y ahora deseaba aparecer ante el mundo como 
Walls visitó también, al gobernador del estado de Chihuahua, Fidel Ávila, al secretario de gobierno, Federico González Garza, al comandante militar, Manuel Chao, al presidente municipal, al cónsul de Estados Unidos: Marion Letcher, ${ }^{60}$ al vicecónsul inglés: E. S. Scobell, a Francisco Lagos Cházaro, director del periódico La Vida Nueva, y al propio Federico Moyo, quien había sido el encargado de conducir a El Paso a los españoles expulsados de Chihuahua. Para los fines de la misión de Walls este acercamiento resultaba importante, pues Moyo le informó que el $99 \%$ de los españoles residentes en el estado no se habían mezclado en política. Así, Walls obtuvo la seguridad de que la expulsión se debió a venganzas personales "ocasionadas sí por la indiscreción de los más de nuestros compatriotas que no midieron el valor y alcance de sus intempestivas peroraciones". 61

Sin embargo, aprovechando la buena disposición de Villa durante la pri-

humanitario y progresista. En cuanto a las tropas, las consideraba "más vigorosas $y$ fuertes" que en otras partes del país, y mejor equipadas por la facilidad que para ello ofrecía la vecindad con Estados Unidos. Asimismo, observaba que el ejército villista contaba en sus filas con oficiales norteamericanos e italianos y médicos alemanes.

60 A Walls le parecio "una persona muy sensata y conocedora del país, pero por esta razón no goza de las simpatías de mister Bryan, que desea lo informen según su manera de ver los asuntos de México y no como realmente son". Consideraba que las opiniones de ambos concordaban respecto a los revolucionarios mexicanos y a los móviles de la revolución. "Informe núm 23, 15 de septiembre de 1914", AHMAE: H-2559.

61 "Informe núm. 22, 14 de septiembre de 1914", AHMAE: H-2559. mera entrevista, en la siguiente, Walls presentó las mismas peticiones que a Carranza: garantías para los españoles y juicio, en presencia de un representante del gobierno español, a aquellos que faltaron a la neutralidad para darles oportunidad de presentar pruebas de descargo. Villa las aceptó sin cortapisas y dejó para después la redacción y firma de un documento alusivo. ${ }^{62}$

La presencia de Obregón en Chihuahua no presagiaba nada bueno, sólo hacía evidente que las relaciones entre Carranza y Villa no mejoraban y, lo que era más grave, que seguían empeorando pues el propio villa le confió a Walls que había amenazado a Obregón con fusilarlo si no se resolvía el conflicto de Sonora. ${ }^{63}$ De modo que

62 "Informe núm. 24, 16 de septiembre de 1914", AHMAE: H-2559.

63 En Sonora el gobernador José María Maytorena consideraba disminuidas sus facultades por el nombramiento de Plutarco Elías Calles como comandante militar de Hermosillo y de las fuerzas fijas del estado; el problema ya había sido mencionado en el Pacto de Torreón, pero se había agravado porque la guamición de Navojoa y las tribus yaquis apoyaron a José María Maytorena y atacaron los poblados de la frontera en poder de Calles. En este momento, Obregon y Villa acordaron sustiruir a Maytorena y trasladar a Calles al estado de Chihuahua. El conflicto no acababa de resolverse y Obregón regresó a la capital chihuahuense para concluirlo de una vez y convencer a Villa de que asistiera a la convención convocada por Carranza, a la que villa se resistía a acudir. Despúes de numerosas discusiones y altercados entre los dos jefes, en los que estuvo a punto de perder la vida Obregón, éste salio de regreso para la ciudad de México el día 21 de septiembre, no sin una nueva amenaza de caer prisionero en manos de Villa. Pocos días después el rompimiento entre Villa y Carranza sería inevitable. Véase Ulloa, Revolución, 1979, pp. 19-21; Cumberland, Revolucton, 1983, pp. $144 \mathrm{ss}$. 


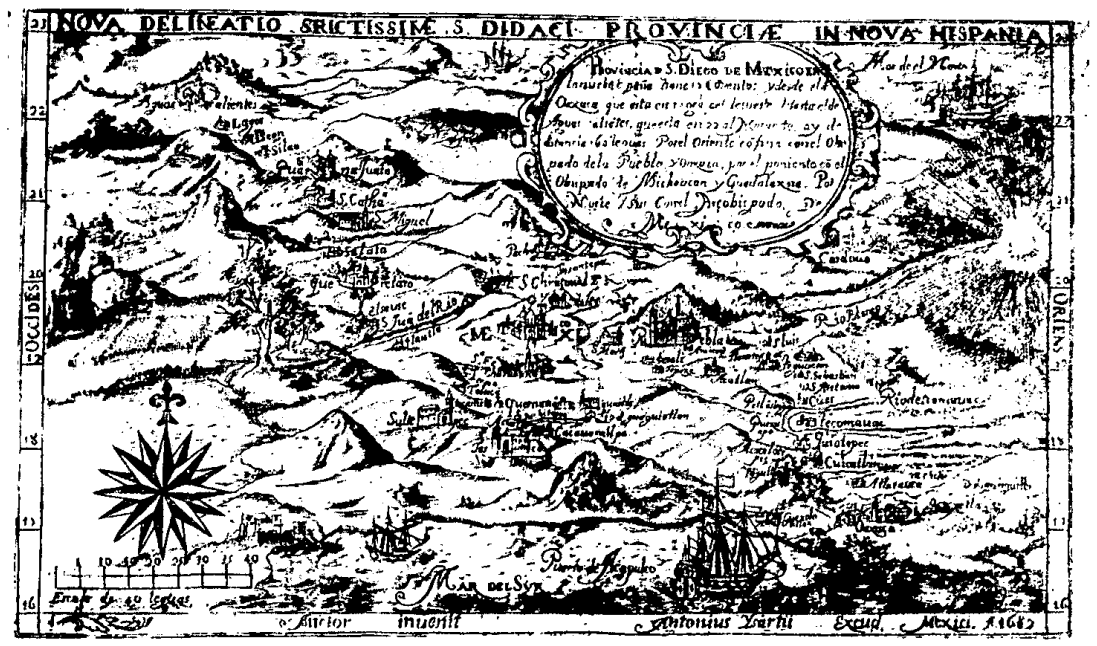

no había tiempo que perder $y$, finalmente, Villa firmó un documento fechado el 19 de septiembre en el cual se asentaba que, "habiendo pasado felizmente" las causas que originaron la ex. pulsión de los españoles del territorio villista, disponía que a éstos se les permiticra regresar y se les devolvieran sus bienes y propiedades. Asimismo, indicaba que se debía juzgar a aquellos contra los que hubiera cargos, con la asistencia de un representante del gobierno español, "en la inteligencia de que a los que les resulte alguna culpabilidad no podrán hacer ninguna reclamación por los perjuicios que hayan sufrido". ${ }^{64}$ El contenido de este documento fue complementado con una campaña en el periódico de La-

64 AнMAE. H-2559. "Informe núm. 26, 19 de septiembre de 1990 ." gos Cházaro, promovida por Walls, en el sentido de destacar la pertinencia de restablecer los tribunales ordinarios de justicia. ${ }^{65}$

\section{El futuro en la mira}

Para responder a las circunstancias por las que pasaba México en esos momentos, y sin considerar para nada la repatriación de los españoles -pues, por el contrario, el agente tenía en mente el regreso a territorio mexicano de los españoles expulsados-, Walls proponía las líneas a seguir por la política exterior de España hacia México, lo que no le resultaba grato. Como primer paso, veía la oportuni-

65 AHMAE. H-2559. "Informes núm. 26 y 27, 19 y 21 de septiembre de 1914." 
dad -que más bien era una necesidad urgente- de nombrar tres cónsules de carrera, debidamente pagados "para proteger y dirigir" a la colonia española únicamente en la región norte del país. ${ }^{66}$ Censuraba que el crecido número de españoles y "lo valioso de sus propiedades" hubiera sido puesto bajo la dirección, consejo y protección de cónsules honorarios, ya que éstos atendían preferentemente sus intereses particulares antes que las necesidades de la colonia. ${ }^{67}$

El consejero de la embajada de España en Estados Unidos sugería también que se nombrara en México un ministro de "excepcionales cualidades" -lo que implicaba que debía mantenerse la representación diplomática-, que pudiera atraerse el afecto de los integrantes de la colonia, que lograra la unión de sus miembros y que tuviera, además, muy presente la susceptibiliclad de "estas gentes [los mexicanos], aun las más bajas, y el tacto exquisito que se requiere para ser superior ante ellos sin manifestarlo".68 $\mathrm{Y}$, por si estas cualidades no fueran suficientes, frente al crecido número de agentes confidenciales que Estados Unidos tenía en México -cada uno con misión diferente- el nuevo ministro debía saber cómo tratar a los nortea-

66 Los puntos de residencia serían San Luis Potosí, "una verdadera provincia española", Tampico y Torreón, el consulado de esta última ciudad tendría jurisdicción en Monterrey, Chihuahua, Durango y Saltillo. AHMAE. H-2559. "Informes núm. 1 y 15, 22 de julio y 28 de agosto de 1914."

67 "Informe núm. 15, 28 de agosto de 1914", AHMAE: H-2559.

68 "Informe núm. 10, 16 de agosto de 1914", AHMAE: H-2559. mericanos. Asimismo, Walls consideraba que la cantidad de trabajo de la legación mexicana, así como su importancia y carácter excepcional, reclamaba más de un secretario que, por otra parte, en su opinión y por esas razones, debía ser un diplomático de carrera. 69

Por supuesto, señalaba la urgencia de nombrar al cónsul de la zona de Chihuahua. Dos hechos resultaban inminentes: el regreso de los españoles al país y el rompimiento entre $V_{i}$ lla y Carranza. La única manera de no poner en peligro el éxito alcanzado en su gestión era estar preparados con un representante español que afrontara las eventualidades que tal fractura pudiera implicar. Por ello, Walls tenía previsto que, en tanto se resolviera lo relativo al gobierno definitivo en México y su reconocimiento por parte de España, esos representantes podrían recibir el nombramiento de agentes comerciales. Lo importante era no dejar a la colonia española sin protección ni consejo. ${ }^{70}$

Una de las opiniones más interesantes que Walls ofreció fue la sugerencia de que el gobierno español estudiara la conveniencia de que los españoles en México se nacionalizaran, ya que

todos son buenos españoles: todos o la mayor parte, casados con mujer mexicana y sus hijos son ya en su mayoría y muy lógicamente, mexicanos. Ahora bien, si cuando se hubieran arreglado las cuestiones económicas, los

69 "Informe núm. 13, 25 de agosto de 1914", AHMAE: H-2559.

70 "Informe núm. 19 y 24, 12 y 16 de septiembre de 1914", AHMAE: H-2559. 
españoles en México se nacionalizaran, su influencia en la política sería tan grande que el prestigio de España adquiriría una preponderancia inmensa para los nuevos inmigrantes, sin que por ello se enfriaran los lazos que con la Madre Patria los une y los inmensos beneficios que sus deudos de allá obtienen de sus parientes "Ios indianos". 71

Tal sugerencia implicaba, por un lado, que se reconocía que los inmigrantes se integraban y arraigaban en estas tierras y, por consiguiente, no regresarian a España; también existía la convicción de que España se beneficiaba económicamente con el proceso migratorio y que no estaba en posibilidades de detenerla; por otro lado, ponía de manifiesto la certeza en la superioridad de los españoles, lo que les haría posible destacar en México; y por último, el interés que se tenía de que España ejerciera un liderazgo no sólo en México sino en el nuevo mundo. Walls insistía en que era indispensable abandonar la pasividad de la política española, pues el número de españoles en México y la cuantía de sus bienes exigían mayores "cuidados", de lo cual dependía su "prestigio en este continente". ${ }^{72}$
71 "Informe núm. 15, 28 de agosto de 1914", AHMAB: H-2559.
72 "Informe núm. 19, 2 de septiembre de 1914", AHMAE: H-2559.

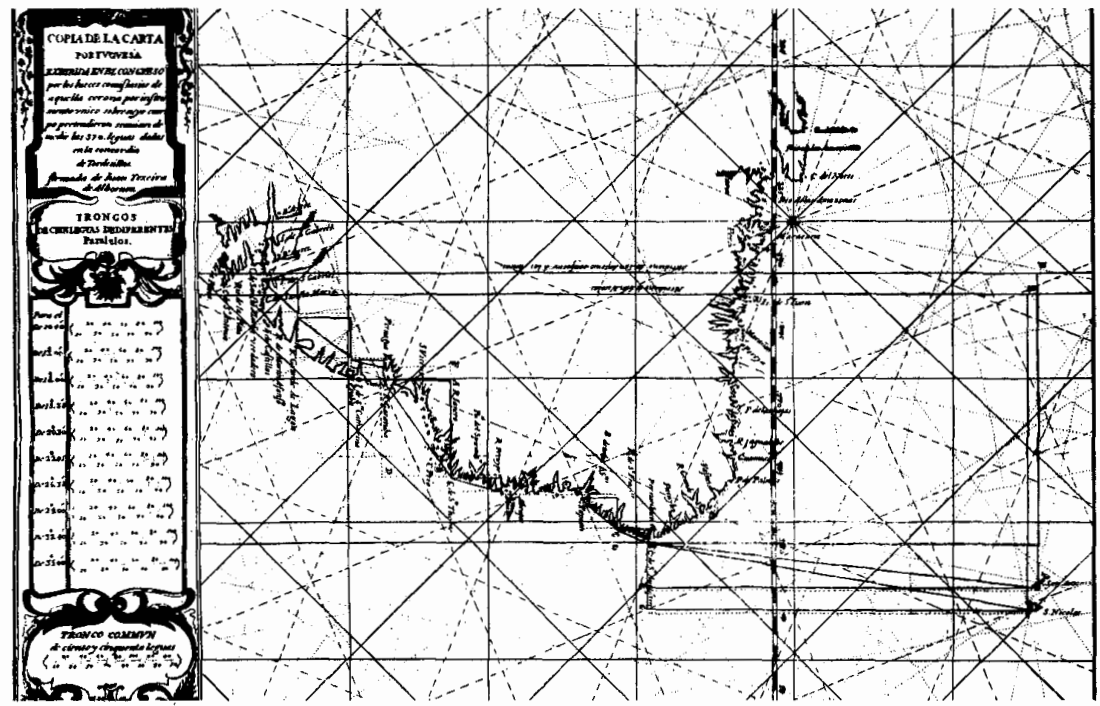




\section{El regreso a Estados Unidos}

El último informe de Walls está fechado el 26 de septiembre de 1914 en El Paso. En él menciona que estaba ya próxima su salida para Washington. Para ese momento, se sabía ya que España había decidido nombrar agente confidencial ante el gobierno de Carranza a José Caro, a punto de llegar a México, mientras que oficiosamente -cuando menos en los primeros tiempos-Ángel de Caso permanecería al lado de Villa.

Walls, por su parte, parecía dar por concluida su misión con un agotamiento completo. Pero, a la vez, se sentía sumamente complacido por los triunfos alcanzados. Sin instrucciones precisas al respecto, y sólo con los objetivos de su cometido delimitados, había salido airoso en todos sentidos: la colonia se mostraba satisfecha, los dos principales líderes -incluido el que más persistentemente hostigó a los españoles-, no sólo habían dado toda clase de garantías a éstos, sino que dieron marcha atrás en algunas de las medidas tomadas en su contra y, además, había hecho "menos violenta" para el nuevo representante español la realización de sus funciones. Así lo hacía ver Riaño al ministro de Estado español, basándose no sólo en los informes del agente, su consejero en la embajada, sino también en lo que otras personas le comunicaban:

Parece ser, según esto, que la misión del señor Walls ha producido excelente efecto, y que se ha conquistado las simpatías de todos los que han tenido ocasión de tratarle, augurando el señor Carothers los resultados más halagüeños de la labor que en México está realizando. ${ }^{73}$

Sin duda, la lucha armada que siguó asolando a México en los años siguientes volvió a afectar intereses españoles. Pero por parte de carrancistas y villistas hubo un cambio de actitud que, según creemos, se debió en buena medida a la oportuna gestión de Manuel Walls y a la atingencia con que la realizó. ${ }^{74}$

El 26 de noviembre de 1915, el rey de España Alfonso XIII reconoció al gobierno de facto de Venustiano $\mathrm{Ca}$ rranza, y ni siquiera la expulsión que

73 Carothers era agente confidencial norteamericano en el frente villista. "Riaño al ministro de Estado, 7 de agosto de 1914", AHMAE: H-2559.

${ }^{74}$ En opinión de Illades, Presencia española, 1991 , p. 132, "la política de Carranza fue cambiante: en un principio los trato [a los españoles] con dureza tratando de responder a las demandas populares en ese sentido[...] En cambio, al final de su gobierno, obedeciendo los dictados de la realpolitik fue más suave y benévolo con los residentes españoles". Por mi parte no creo que haya existido una par. ticular demanda popular que atender por parte de Carranza, si bien los descontentos del pueblo se manifestaron espontáneamente en múltiples ocasiones; tampoco pensamos que con el tiempo su política exterior se hubiera suavizado. La doctrina Carranza dejo de lado los intereses económicos extranjeros en tanto quedara a salvo la soberanía nacional y los extranjeros no se inmiscuyeran en la política interna del país. En ningún momento parece existir en el Primer Jefe el deliberado propósito de afectar los bienes extranjecos; cuando logro estabilidad y que se reconociera -de alguna manerasu gobierno, bajó la presion y trató de mantener relaciones cordiales con el exterior, no así cuando se trató de resolver la situación mexicana desde fuera, en esas ocasiones fue categórico e intransigente. 
éste decretó en contra de Ángel de Caso, por considerársele no grato, puso en peligro las relaciones entre México y España durante este periodo. La colonia española pudo así permanecer en México, cuidando sus intereses con el mismo sobresalto que el resto de los mexicanos, quienes también arriesgaban y sufrían con la revolución pero que no podían, ni querian, escapar a ella. ${ }^{75}$

\section{Bibliografía}

-Bojórquez, Juan de Dios, La inmigración española en México. Conferencia susten. tada ante el Grupo Cultural "Jovellanos", del Centro Asturiano de México, el domingo 25 de septiembre de 1932, Ediciones Especiales de Crisol, México, 1932.

-Cumberland, Charles, La revolución mexicana: los años constitucionalistas,

75 Los datos que Bojorquez, Inmigracion, 1932 , p. 15 , ofrece respecto de la entrada y salida de españoles en México entre 1911 y 1915 es muy ilustrativa, pues puede apreciarse que éstos no salieron en su totalidad huyendo del país, ni se suspendió la inmigración, como seguramente hubiera ocurrido si el antihispanismo se hubiera desbordado. Las cifras son las siguientes:

$\begin{array}{ccc}\text { Año } & \text { Entrada } & \text { Salida } \\ 1911 & 5269 & 5065 \\ 1912 & 5321 & 5073 \\ 1913 & 4487 & 4460 \\ 1914 & 1393 & 1609 \\ 1915 & 1856 & 3175\end{array}$

por su parte, Gamboa Ojeda, Empresarios, 1985 , p. 193 , hace notar que varios industriales españoles salieron de Puebla durante la revolución, pero sólo tiene certeza de dos: Francisco de Velasco y Andrés Mastuerzo. El primero se fue a Cuba de 1914 a 1917 y el segundo, a Cuba y luego a Nueva York, para regresar en 1919; es decir, si bien salieron, no fue permanentemente. introducción y material añadido por David C. Bailey, Fondo de Cultura Económica, México, 1983.

-Díaz, Luis Miguel y Jaime G. Martini (comps.), Relaciones diplomáticas México-España. 1821-1977, Porrúa, México, 1977.

-Diario de las Sesiones de Cortes. Cámara de los Diputados, Legislatura de 1914 que dio principio el 2 de abril, t. III, núms. 24-33, Establecimiento Tipográfico de los Sucs. de J. A. García, Madrid, 1914.

-Fabela, Isidro, Historia diplomática de la revolución mexicana, 2 vols., Instituto Nacional de Estudios Históricos de la Revolución Mexicana, México, 1985 (edición facsimilar).

-Fuentes Mares, José, Historia de dos orgullos, Editorial Océano, México, 1984.

-Gamboa Ojeda, Leticia, Los empresa. rios de ayer. El grupo dominante en la industria textil de Puebla, 1906-1929, Centro de Investigaciones Históricas-UAP, Puebla, 1985.

-González Loscertales, Vicente, "Bases para el análisis de la colonia española de México en 1910", Revista de Indias, núms. 155-158, enero-diciembre de 1979 , pp. 267-295.

"Ia colonia española de México durante la revolución maderista. 1911-1913", Revista de la Universidad Complutense, vol. XXvi, núm. 107, eneromarzo de 1977 , pp. 341-356.

, El empresarto español Puebla. 1880-1916; surgimiento y crisis de un grupo de poder, s.p.i. (mecanuscrito).

- Illades, Carlos, Presencia española en la revolución mexicana, tesis de maestría, UNAM, México, 1988.

Presencia española en la revolución mexicana, 1910-1915, Instituto de Investigaciones Dr. Jơsé María Luis Mora, México, 1991.

-Lida, Clara E. (coord.), Tres aspectos de la presencia española en México du. 
rante el porfiriato. Relaciones económicas, comerciantes y población, El Colegio de México, México,1981.

-Katz, Friedrich, La guerra secreta en México, 2 vols., Era, México, 1982.

-Mac Gregor, Josefina, México y España: 1919-1913, tesis de maestría, UNaM, México, 1991 (en prensa en el Instituto Nacional de Estudios Históricos de la Revolución Mexicana).

-Pérez Herrero, Pedro, "Algunas hipóte. sis de trabajo sobre la inmigración española a México: los comerciantes", en Clara E.
Lida (coord.), Tres aspectos de la presencla española en México durante el porfiriato. Relaciones económicas, comerciantes y población, El Colegio de México, México, 1981, pp. 103-177.

-Richmond, Douglas, "Confrontation and reconciliation, mexican and spaniards during the mexican revolution, 19101920", Tbe Americas, vol. XLI, núm. 2, octubre de 1984, pp. $215-228$.

-Ulloa, Berta, La revolución escindida, El Colegio de México, México, 1979 (Historia de la Revolución Mexicana, 4). 